\title{
Test of the Rosetta Pedotransfer Function for Saturated Hydraulic Conductivity
}

\author{
Carlos Alvarez-Acosta ${ }^{1}$, Robert J. Lascano ${ }^{1}$, Leo Stroosnijder ${ }^{2}$ \\ ${ }^{1}$ USDA-ARS ${ }^{*}$ Cropping System Research Laboratory, Wind Erosion and Water Conservation Research Unit, Lubbock, USA; ${ }^{2}$ Land \\ Degradation and Development Group, Soil Science Centre, Wageningen University, Wageningen, Netherlands. \\ Email: carlosalvarez83@gmail.com, Robert.Lascano@ars.usda.gov,Leo.Stroosnijder@wur.nl
}

Received April 28 $8^{\text {th }}, 2012$; revised May 30 ${ }^{\text {th }}, 2012$; accepted June $10^{\text {th }}, 2012$

\begin{abstract}
Simulation models are tools that can be used to explore, for example, effects of cultural practices on soil erosion and irrigation on crop yield. However, often these models require many soil related input data of which the saturated hydraulic conductivity $\left(K_{s}\right)$ is one of the most important ones. These data are usually not available and experimental determination is both expensive and time consuming. Therefore, pedotransfer functions are often used, which make use of simple and often readily available soil information to calculate required input values for models, such as soil hydraulic values. Our objective was to test the Rosetta pedotransfer function to calculate $K_{s}$. Research was conducted in a 64-ha field near Lamesa, Texas, USA. Field measurements of soil texture and bulk density, and laboratory measurements of soil water retention at field capacity $(-33 \mathrm{kPa})$ and permanent wilting point $(-1500 \mathrm{kPa})$, were taken to implement Rosetta. Calculated values of $K_{s}$ were then compared to measured $K_{s}$ on undisturbed soil samples. Results showed that Rosetta could be used to obtain values of $K_{s}$ for a field with different textures. The Root Mean Square Difference (RMSD) of $K_{s}$ at $0.15 \mathrm{~m}$ soil depth was $7.81 \times 10^{-7} \mathrm{~m} \cdot \mathrm{s}^{-1}$. Further, for a given soil texture the variability, from $2.30 \times$ $10^{-7}$ to $2.66 \times 10^{-6} \mathrm{~m} \cdot \mathrm{s}^{-1}$, of measured $K_{s}$ was larger than the corresponding RMSD. We conclude that Rosetta is a tool that can be used to calculate $K_{s}$ in the absence of measured values, for this particular soil. Level H5 of Rosetta yielded the best results when using the measured input data and thus calculated values of $K_{s}$ can be used as input in simulation models.
\end{abstract}

Keywords: Rosetta; Saturated Hydraulic Conductivity; $K_{s}$; Pedotransfer Function

\section{Introduction}

In order to model soil physical processes related to soilwater content, it is important to know the hydraulic properties of the soil [1]. Vigiak et al. [2] also remarked the importance of characterizing soil hydraulic parameters in order to understand the occurrence and movement of overland flow at field, hill-slope, and catchment scale. These soil hydraulic properties include the saturated $\left(K_{s}\right)$ and unsaturated hydraulic conductivity, and the water retention curve. Furthermore, in any modeling study on water flow and solute transport in soils, the water retention and hydraulic conductivity functions for soil horizons in the profile are crucial input parameters [3]. Examples of two simulation models that require soil hydraulic properties as inputs are the Energy Water Balance

\footnotetext{
${ }^{*}$ The US Department of Agriculture (USDA) prohibits discrimination in all its programs and activities on the basis of race, color, national origin, age, disability, and where applicable, sex, marital status, familial status, parental status, religion, sexual orientation, genetic information, political beliefs, reprisal, or because all or part of an individual's income is derived from any public assistance program.
}

Model [4,5] and HYDRUS [6,7]. In addition, soil hydraulic properties are a required input in models used to calculate water runoff and soil erosion, e.g. Precision Agricultural Landscape Modeling System [8-10] and examples of other models are given by Aksoy and Kavvas [11].

Although the soil hydraulic properties can be measured directly, this practice is both costly and time-consuming, and sometimes results obtained are unreliable because of the associated soil heterogeneity and experimental errors $[12,13]$. When large areas of land are under study, it is virtually impossible to perform enough measurements to be meaningful, indicating the need for an inexpensive and rapid way to determine soil hydraulic properties [14]. For example, some research results indicated that in a 10-ha field, 1300 measurements would have to be made in order to accurately measure saturated hydraulic conductivity to within $10 \%$ of the mean value [13]. Furthermore, Stroosnijder [15] indicated that measurements alone would provide data difficult to extrapolate in time and space, meaning that erosion in large fields would not 
be known without prediction technologies, but also that predictions need measurements to work. Therefore, many indirect methods such as pedotransfer functions (PTFs) have been developed to reduce the effort and cost [16]. These PTFs are predictive functions of certain soil properties estimated from other simpler measured soil proper-ties [17]. They can be used as inputs to models in order to reduce costs and accelerate the investigations. A detailed review of PTFs is given by Wösten et al. [3] and scaling of soil physical properties in relation to models is given by Pachepsky et al. [18]. In summary, many efforts have been made to develop PTFs at large scale, but little has been done to evaluate the performance of Artificial Neural Networks (ANNs) in estimating saturated $K_{s}$ at a landscape scale [19].

A soil hydraulic property that is often a required input to simulation models is the saturated hydraulic conductivity, $K_{s}$. It is one of the most important soil physical properties for determining infiltration rate and other hydrological processes [20]. In general, the $K_{s}$ refers to the capacity of the soil to drain water and gives information about the presence of disruptive soil strata, and the correlation between the permeability and other soil characteristics. The geometry of the complex pores that depend on texture, structure, viscosity and density, determine the $K_{s}$. In hydrologic models, this is a sensitive input parameter and is one of the most problematic measurements at field-scale in regard to variability and uncertainty [21]. The $K_{s}$ is known to be one of the most variable of all soil physical properties, varying up to 10 orders of magnitude for different geo-materials [22]. Thus, the objective of this study was to determine the applicability of the Rosetta pedotransfer function [14] to calculate $K_{s}$ for different soil textures of a large field in the Texas Southern High Plains. The calculated values of $K_{s}$ were evaluated by comparing them to laboratory-measured values. Furthermore, the differences between measured and calculated values of $K_{s}$ were evaluated using two statistical parameters, the mean square deviation [23] and the Nash Sutcliffe Efficiency parameter [25]. A use of the Rosetta PTF is to assist researchers in studying the hydrological processes that could lead to better water management practices in the region of study. This is important because in the Texas Southern High Plains the combination of common droughts and a declining water table from the Ogallala Aquifer are a challenge to manage the irrigation of crops and establish crops under dryland conditions $[5,25]$.

\section{Materials and Methods}

\subsection{Study Area}

The study area is located in the region known as Llano Estacado, near Lamesa, which is a small town, popula- tion of close to 10,000, located in Dawson County, Texas, USA (Figure 1). The coordinates are $32^{\circ} 32^{\prime} 7.4^{\prime \prime} \mathrm{N}$; $101^{\circ} 46^{\prime} 8.24^{\prime \prime} \mathrm{W}$; and, an elevation of $833 \mathrm{~m}$ above sea level with a semi-arid climate. The field is 63.8 ha and has an average slope of $0.33 \%$, although parts of the field have slopes in excess of $5 \%$. In this region, about half the cultivated land is irrigated from an underground aquifer, called the Ogallala, which is classified, as non-rechargeable [25]. The predominant soil series at this site is an Amarillo fine sandy loam, a fine-loamy, mixed, superactive, thermic, Aridic Paleustalf [26]. These soils are characterized by a high content of $\mathrm{Ca}$ and $\mathrm{Mg}$ carbonates $(\mathrm{pH}>7)$, low organic matter $\left(<2 \mathrm{~g} \cdot \mathrm{kg}^{-1}\right)$, and are classified as moderately permeable.

\subsection{Soil Sampling}

To determine the $K_{s}$ as well as the water retention curve, 18 undisturbed soil samples were collected using a gouge auger, from $0.10-0.15 \mathrm{~m}$ depth from the surface at the locations shown in Figure 2. Sampling was done on 15 July 2009. The sampler rings were $0.05 \mathrm{~m}$ in diameter by $0.051 \mathrm{~m}$ long. For the purpose of this study, only one sample was taken at each of the 18 locations; therefore, they can be considered as replicates.

To determine the textural classes, 36 soil cores were sampled over the field on the 15 July 2009 at the locations shown in Figure 3, which were geo-referenced using a Global Positioning System (Model 4700 Dual Channel RTK system, Trimble, Sunnyvale, CA). These samples were taken with a commercial tractor-mounted hydraulic core sampler system (Giddings Machine Company, Model HDGSRTS, Windsor, CO). This system pushed into the soil a tube-sampler with a plastic sleeve inside, i.e., $1.2 \mathrm{~m}$ long and $0.05 \mathrm{~m}$ in diameter. Once the sampler was removed from the soil the sleeve inside the core was extracted and the undisturbed soil sample obtained. Thereafter, the soil cores were stored in a coldroom at a temperature of $5^{\circ} \mathrm{C}$. These sampling locations were selected using the NRCS (2008) soil map [26] as a guide to ensure that all the different soil types within the field were included in the sampling scheme. The soil cores were used to identify the lower and upper depth of soil horizons (Table 1). This soil was then oven-dried at 105 for $24 \mathrm{hrs}$ and the dry samples were ground with a mill ${ }^{\circ} \mathrm{C}$ and sieved to $2 \mathrm{~mm}$.

\subsection{Rosetta Description}

Rosetta is an algorithm that calculates soil water retention parameters, $K_{s}$ and unsaturated hydraulic conducti-

\footnotetext{
${ }^{1}$ Mention of this or other proprietary products is for the convenience of the readers only, and does not constitute endorsement or preferential treatment of those products by USDA-ARS.
} 


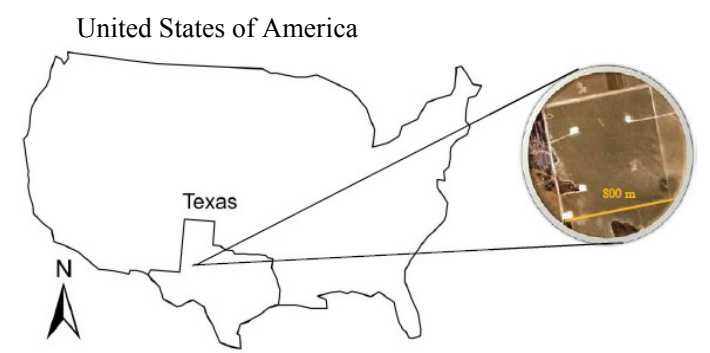

Figure 1. Location of the field-study, Lamesa, Dawson county, Texas, USA. (Source: Self composition on a GoogleUSDA farm service agency image).

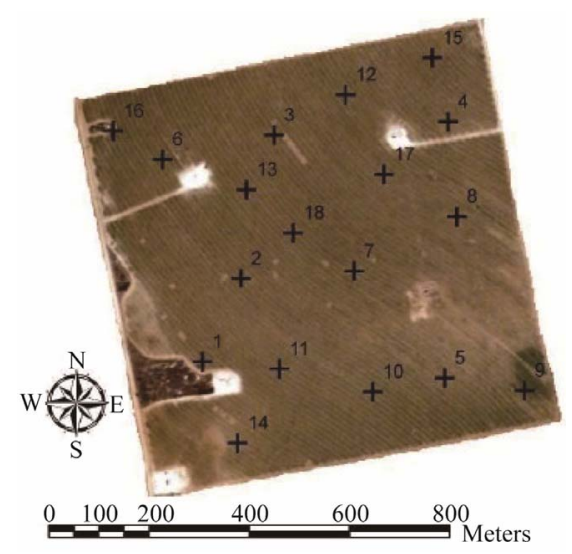

Figure 2. Sampling locations in the field where 18 soil cores were obtained and saturated hydraulic conductivity $\left(K_{s}\right)$, and water retention were measured. (Source: Self composition on a Google-USDA farm service agency image).

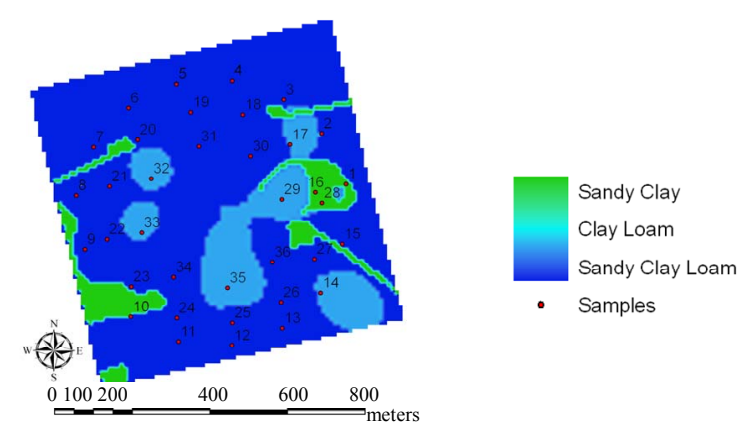

Figure 3. Spatial distribution of the textural classes in Lamesa, Texas.

Table 1. Upper and lower depth limits of the soil horizons for the $\mathbf{1 8}$ soil cores taken at the field in Lamesa, Texas.

\begin{tabular}{ccc} 
Soil horizon & Upper limit $(\mathrm{m})$ & Lower limit $(\mathrm{m})$ \\
\hline $1 \mathrm{Ap}$ & 0.0 & 0.3 \\
$2 \mathrm{Ap}$ & 0.1 & 0.3 \\
$1 \mathrm{Bt}$ & 0.2 & 0.5 \\
$2 \mathrm{Bt}$ & 0.3 & 1.2 \\
$3 \mathrm{Bt}$ & 0.4 & 1.2 \\
$\mathrm{Btk}$ & 0.5 & 1.2 \\
Btkk & 0.5 & 1.2 \\
\hline
\end{tabular}

vity using hierarchical PTFs based on five levels of input data [14]. It is of great practical use, allowing flexibility for the user towards the required input data [27]. The first level (H1) consists of a lookup table that provides average parameters for each of the USDA textural classes. The second level (H2) uses values from $\mathrm{H} 1$ plus sand, silt, and clay fractions as inputs, and provides a hydraulic parameter that varies continuously with texture. The third level (H3) includes the predictors used in level H2 and the soil dry-bulk density $\left(\rho_{\mathrm{d}}\right)$. The fourth level (H4) uses $\mathrm{H} 3$ and soil volumetric water content $(\theta)$ at a water suction of $-33 \mathrm{kPa}$. The last level (H5) consists of all the other parameters, $\mathrm{H} 4$, plus the $\theta$ at a water suction of $-1500 \mathrm{kPa}$. While $\mathrm{H} 1$ is a simple table with average hydraulic parameters for each textural class, all other models involve a combination of neural networks and the bootstrap method [14].

In Rosetta, the relation between $\theta$ and water suction (h), i.e. water retention $[\theta(h)]$, as well as the saturated and unsaturated hydraulic conductivity, are described with the well known Mualem-Van Genuchten equation $[28,29]$ and is given by:

$$
\theta(h)=\theta_{r}+\frac{\left(\theta_{s}-\theta_{r}\right)}{\left[1+(\alpha \times h)^{n}\right]^{m}}
$$

where $\theta(h)$ is the soil volumetric water content $\left(\mathrm{m}^{3} \cdot \mathrm{m}^{-3}\right)$ at suction $\mathrm{h}(\mathrm{cm}) ; \theta_{s}$ and $\theta_{r}$ are the saturated and the residual water content $\left(\mathrm{m}^{3} \cdot \mathrm{m}^{-3}\right)$ at $h=0 \mathrm{~cm}$ and $-15,000$ $\mathrm{cm}$, respectively; $\alpha\left(>0\right.$ in $\left.\mathrm{cm}^{-1}\right)$ is related to the inverse of the air entry suction; and $n(>1)$ is a measure of the pore-size distribution and $\mathrm{m}=1-1 / \mathrm{n}$. The unsaturated hydraulic conductivity, $K\left(S_{e}\right)$, is described with the Mualem-Van Genuchten model as:

$$
K\left(S_{e}\right)=K_{0} S_{e}^{L}\left[1-\left(1-S_{e}^{\left(\frac{n}{n-1}\right)}\right)^{m}\right]^{2}
$$

where $K_{0}$ is a fitted value of $K$ at saturation $\left(\mathrm{cm} \cdot \mathrm{d}^{-1}\right)$, which is similar but not considered equal to $K_{s}$, and $L$ is a pore connectivity factor (negative in most cases). The effective saturation $\left(S_{e}\right)$ is given by:

$$
S_{e}=\frac{\left(\theta(h)-\theta_{r}\right)}{\left(\theta_{s}-\theta_{r}\right)}=\left[\frac{1}{1+(\alpha \times h)^{n}}\right]^{m}
$$

Therefore, the relative hydraulic conductivity $K_{r}(h)$ is given by:

$$
K_{r}(h)=\frac{\left[1-(\alpha \times h)^{n-1}\left[1+(\alpha \times h)^{n}\right]^{m}\right]^{2}}{\left[1+(\alpha \times h)^{n}\right]^{\frac{m}{2}}}
$$

which is a function given the quotient of hydraulic con- 
ductivity function, $K(h)$ to saturated hydraulic conductivity, $K_{s}$ [27]. In summary, the seven parameters calculated with the Rosetta PTF (Equations (1)-(4)) are: $\theta_{r}, \theta_{s}, \alpha, n$, $K_{s}, K_{0}$, and $L$.

\subsection{Model Performance Evaluation}

Calculated values of $K_{s}$ obtained with Rosetta were compared to corresponding measured values and evaluated using two statistical parameters. First, by using the Root Mean Squared Difference (RMSD) and second, by using the Nash Sutcliffe Efficiency (NSE). The RMSD, gives the mean difference between measured and calculated values of $K_{s}$ and is calculated as [23]:

$$
\operatorname{RMSD}=\sqrt{\frac{1}{n} \sum_{i=1}^{n}\left(x_{i}-y_{i}\right)^{2}}
$$

where $x_{i}$ is the measured value of $K_{s}$ and $y_{i}$ is the corresponding calculated value of $K_{s}$ obtained with Rosetta.

The NSE compares measured and calculated values of $K_{s}$ and is given by [24]:

$$
\mathrm{NSE}=1-\left[\frac{\sum_{i=1}^{n}\left(Y_{i}^{m}-Y_{i}^{c}\right)^{2}}{\sum_{i=1}^{n}\left(Y_{i}^{m}-Y_{i}^{\text {mean }}\right)^{2}}\right]
$$

where $Y_{i}^{m}$ is measured value of $K_{s}$ and $Y_{i}^{c}$ is the corresponding calculated value of $K_{s}, Y_{i}^{\text {mean }}$ is the average of measured values of $K_{s}$, and $n$ is number of measurements. Values of NSE may range from $-\propto$ to 1 . A value of NSE $=1$, corresponds to a perfect match of calculated compared to the measured values of $K_{s}$. Conversely, an efficiency of $0(\mathrm{NSE}=0)$ indicates that the Rosetta calculations of $K_{s}$ are as accurate as the mean of the measured data; whereas, an efficiency $<0$ (NSE $<0$ ) occurs when the measured mean is a better predictor than the model or, in other words, when the residual variance, described by the nominator in Equation (6), is larger than the data variance, described by the denominator [24].

\subsection{Measurements}

Textural Analysis. Clay, silt and sand fraction of all 36-soil samples were determined using the hydrometer method [30]. This method uses the Navier-Stokes equation to calculate soil particles in suspension in an infinite soil column and is adequate for textural class identification, but cannot be used to accurately define the particle size [31]. Nevertheless, it provides a reasonable input to Rosetta [14].

Saturated Hydraulic Conductivity $\left(K_{s}\right)$. The $K_{s}$ was measured under laboratory conditions using the constant and falling head methods [31] on undisturbed soil samples. For both methods, $K_{s}$ were measured using a laboratory permeameter [32]. In some soil samples, water flowed in the range of operation for the falling head method, while in other samples the water flowed in the range of the constant-head method. For this reason, both methods were used and thereafter matched to the $K_{s}$ of each soil sample. Our first approach was to use the constant head method and if $K_{s}$ was $<1.16 \times 10^{-7} \mathrm{~m} \cdot \mathrm{s}^{-1}$, the falling head method was selected. As previously described, the undisturbed soil samples used for the measurement of $K_{s}$ were collected using a gouge auger at the locations shown in Figure 2. To avoid the possible disintegration of soil particles in each sample, which would cause silting of the pores and a reduction of the flow and $K_{s}$, we used ultrahigh-pure water that was autoclaved at $120^{\circ} \mathrm{C}$ for 30 minutes. The solution was saturated with calcium sulphate $\left(\mathrm{CaSO}_{4} \cdot 2 \mathrm{H}_{2} \mathrm{O}\right)$ and toluene was added to eliminate microorganisms.

Water Retention Determination. The relation between soil volumetric water content $(\theta)$ and water suction $(h)$ at saturation $(h=0)$ and field capacity $(h=-33 \mathrm{kPa})$ was measured using a sand/kaolin box (pF-Determination, Eijkelkamp, Giesbeek, The Netherlands), that operates in the $0-50 \mathrm{kPa}$ range [33]. For these two measurements we used the undisturbed soil samples that were also used to measure $K_{s}$. Weights of the soil samples, before and after drying, and ring volumes were used to calculate the soil gravimetric water content $\left(\theta_{\mathrm{g}}, \mathrm{kg} \cdot \mathrm{kg}^{-1}\right)$ and the corresponding value of the soil dry-bulk density $\left(\rho_{\mathrm{d}}, \mathrm{kg} \cdot \mathrm{m}^{-3}\right)$ was used to convert $\theta_{\mathrm{g}}$ to $\theta$, assuming a density of water equal to $1000 \mathrm{~kg} \cdot \mathrm{m}^{-3}$.

For the soil water content at wilting point, $\mathrm{pF}=4.18(h$ $=-1500 \mathrm{kPa} \approx-15 \mathrm{bar}$ ), the water in the soil is retained in small pores, and thus the retention of water is dominantly influenced by texture. For this reason, disturbed soil samples can be used for this determination, which were saturated with water for $2-3$ days and placed on a plate (Pressure-Membrane Apparatus, Eijkelkamp, Giesbeek, The Netherlands) and a pressure of $1500 \mathrm{kPa}$ was applied for 3 days to the three replicates [34]. Afterwards soil samples were weighed (wet mass), oven-dried at $105^{\circ} \mathrm{C}$ and weighed again (dry mass). With these values the $\theta_{\mathrm{g}}$ water content, was calculated for a $\mathrm{pF}=4.18$, and converted to $\theta$ using the $\rho_{\mathrm{d}}$ of the undisturbed samples used in the sand/kaolin box.

\section{Results and Discussion}

\subsection{Measurements}

There were three textural classes corresponding to the 18 spots where undisturbed soil samples were taken (Figure 2) and these were: clay loam, sandy clay loam, and sandy clay. Of the total number of soil samples, there were thirteen samples of sandy clay loam, four of clay loam and one sandy clay. The ESRI software (version 9.2) of ArcGIS (2006) was used as the Geographic Information 
System (GIS) processing software, and the inverse distance weighed interpolation was used to extend the measured values of texture across the entire field. Figure 3 shows the textural classes at a $0.15 \mathrm{~m}$ depth, showing that most of the field is classified as a sandy clay loam.

The field has five distinct areas (see Figure 2) with oil wells and access roads that are not cultivated. These areas were included in our analysis as they contribute to the hydrological processes of the entire field, and were assigned a textural class of sandy clay.

Values of soil volumetric water content $(\theta)$ as a function of $\mathrm{h}$ measured with the kaolin/sand box and pressure membrane are shown in Table 2 using the 18 undisturbed soil samples taken from the $0.10-0.15 \mathrm{~m}$ soil layer. These results show that the sandy clay retains more water at saturation and this is probably related to the porosity, which is also the highest (45.5\%) among the soil samples taken. The soil $\theta$ at $h=-33 \mathrm{kPa}$ and $h=-1500$ $\mathrm{kPa}$ given in Table 2 were used as inputs to the Rosetta PTF.

Values of soil dry-bulk density $\left(\rho_{\mathrm{b}}\right)$ for each textural class and its porosity, calculated assuming a particle density of $2650 \mathrm{~kg} \cdot \mathrm{m}^{-3}$ are shown in Table 3. The sandy clay had the lowest $\rho_{\mathrm{b}}$ and thus the highest porosity. High values of $\rho_{\mathrm{b}}$ in the sandy clay loam samples lowered the calculated porosity affecting the hydraulic properties of the corresponding horizon.
Measured values of saturated hydraulic conductivity $\left(K_{s}\right)$ for each of the 18 locations of Figure 2 are given in Table 4 and plotted in Figure 4. Values of $K_{s}$ ranged

Table 2. Average soil volumetric water content $\left(\theta, \mathrm{m}^{3} \cdot \mathrm{m}^{-3}\right)$ and standard deviation (SD) as a function of $h$ at $0,-33$ and $-1500 \mathrm{kPa}$ for the three textural classes in Lamesa, Texas.

\begin{tabular}{cccc}
\hline $\begin{array}{c}\text { Textural class } \\
\text { (number of samples) }\end{array}$ & \multicolumn{3}{c}{ Soil volumetric water content } \\
& 0 & -33 & -1500 \\
& $h(\mathrm{kPa})$ & $h(\mathrm{kPa})$ & $h(\mathrm{kPa})$ \\
& 0.45 & 0.30 & 0.17 \\
Clay loam (Cl) (4) & $(0.03)$ & $(0.02)$ & $(0.05)$ \\
& 0.49 & 0.27 & 0.14 \\
Sandy clay (SC) (1) & $(0.00)$ & $(0.00)$ & $(0.00)$ \\
& 0.45 & 0.29 & 0.15 \\
Sandy clay loam (SCL) (13) & $(0.04)$ & $(0.02)$ & $(0.05)$ \\
\hline
\end{tabular}

Table 3. Average measured soil dry-bulk density $\left(\rho_{\mathrm{b}}, \mathrm{kg} \cdot \mathrm{m}^{-3}\right)$ and calculated porosity (\%), and standard deviation (SD) for the textural classes in Lamesa, Texas.

\begin{tabular}{ccc}
$\begin{array}{c}\text { Textural class } \\
\text { (samples) }\end{array}$ & $\begin{array}{c}\rho_{\mathrm{b}} \\
\left(\mathrm{kg} \cdot \mathrm{m}^{-3}\right)\end{array}$ & $\begin{array}{c}\text { Porosity } \\
(\%)\end{array}$ \\
\hline Clay loam (4) & $1620(0.05)$ & $39.0(2.00)$ \\
Sandy clay (1) & $1440(0.00)$ & $45.5(0.00)$ \\
Sandy clay loam (13) & $1640(0.09)$ & $38.1(3.50)$ \\
\hline
\end{tabular}

Table 4. Measured and calculated values of $K_{s}$ obtained using the five hierarchical (H) levels of the Rosetta PTF. In the texture (USDA) column $\mathrm{S}$ is for sand, $\mathrm{C}$ is for clay and $\mathrm{L}$ is for loam, and all values of $K_{s}$ have units of $\mathrm{m} \cdot \mathrm{s}^{-1}$.

\begin{tabular}{|c|c|c|c|c|c|c|c|}
\hline Location & $\begin{array}{l}\text { Texture } \\
\text { (USDA) }\end{array}$ & $\begin{array}{c}K_{s} \\
\text { measured }\end{array}$ & $\begin{array}{c}K_{s}-\mathrm{H} 1 \\
\text { USDA textural } \\
\text { class }\end{array}$ & $\begin{array}{l}K_{s}-\mathrm{H} 2 \\
\text { texture }\end{array}$ & $\begin{array}{c}K_{s}-\mathrm{H} 3 \\
\text { texture }+\rho_{\mathrm{b}}\end{array}$ & $\begin{array}{c}K_{s}-\mathrm{H} 4 \\
\text { texture }+\rho_{\mathrm{b}}+\theta_{33}\end{array}$ & $\begin{array}{c}K_{s}-\mathrm{H} 5 \\
\text { texture }+\rho_{\mathrm{b}}+\theta_{33}+\theta_{1500}\end{array}$ \\
\hline 1 & SCL & $3.50 \times 10^{-7}$ & $1.5 \times 10^{-6}$ & $1.5 \times 10^{-6}$ & $9.2 \times 10^{-7}$ & $5.7 \times 10^{-7}$ & $6.4 \times 10^{-7}$ \\
\hline 2 & $\mathrm{CL}$ & $1.30 \times 10^{-6}$ & $9.5 \times 10^{-7}$ & $7.9 \times 10^{-7}$ & $6.9 \times 10^{-7}$ & $8.3 \times 10^{-7}$ & $9.0 \times 10^{-7}$ \\
\hline 3 & SCL & $3.50 \times 10^{-7}$ & $1.5 \times 10^{-6}$ & $1.2 \times 10^{-6}$ & $6.7 \times 10^{-7}$ & $5.2 \times 10^{-7}$ & $5.3 \times 10^{-7}$ \\
\hline 4 & SCL & $3.50 \times 10^{-8}$ & $1.5 \times 10^{-6}$ & $1.1 \times 10^{-6}$ & $4.0 \times 10^{-7}$ & $2.9 \times 10^{-7}$ & $3.7 \times 10^{-7}$ \\
\hline 5 & SCL & $2.30 \times 10^{-6}$ & $1.5 \times 10^{-6}$ & $8.3 \times 10^{-7}$ & $9.4 \times 10^{-7}$ & $2.2 \times 10^{-6}$ & $2.1 \times 10^{-6}$ \\
\hline 6 & SCL & $1.40 \times 10^{-6}$ & $1.5 \times 10^{-6}$ & $9.6 \times 10^{-7}$ & $1.3 \times 10^{-6}$ & $2.4 \times 10^{-6}$ & $2.3 \times 10^{-6}$ \\
\hline 7 & CL & $2.30 \times 10^{-7}$ & $9.5 \times 10^{-7}$ & $1.8 \times 10^{-6}$ & $4.4 \times 10^{-7}$ & $3.4 \times 10^{-7}$ & $3.6 \times 10^{-7}$ \\
\hline 8 & $\mathrm{SC}$ & $3.70 \times 10^{-6}$ & $1.3 \times 10^{-6}$ & $8.8 \times 10^{-7}$ & $1.6 \times 10^{-6}$ & $4.9 \times 10^{-6}$ & $4.1 \times 10^{-6}$ \\
\hline 9 & $\mathrm{CL}$ & $2.30 \times 10^{-7}$ & $9.5 \times 10^{-7}$ & $8.3 \times 10^{-7}$ & $7.0 \times 10^{-7}$ & $6.5 \times 10^{-7}$ & $7.1 \times 10^{-7}$ \\
\hline 10 & $\mathrm{SCL}$ & $5.80 \times 10^{-7}$ & $1.5 \times 10^{-6}$ & $1.1 \times 10^{-6}$ & $9.6 \times 10^{-7}$ & $1.0 \times 10^{-6}$ & $1.0 \times 10^{-6}$ \\
\hline 11 & $\mathrm{SCL}$ & $6.90 \times 10^{-7}$ & $1.5 \times 10^{-6}$ & $9.5 \times 10^{-7}$ & $6.1 \times 10^{-7}$ & $8.8 \times 10^{-7}$ & $8.9 \times 10^{-7}$ \\
\hline 12 & $\mathrm{SCL}$ & $2.70 \times 10^{-6}$ & $1.5 \times 10^{-6}$ & $7.8 \times 10^{-7}$ & $2.7 \times 10^{-7}$ & $2.8 \times 10^{-7}$ & $2.9 \times 10^{-7}$ \\
\hline 13 & CL & $2.20 \times 10^{-6}$ & $9.5 \times 10^{-7}$ & $7.6 \times 10^{-7}$ & $7.0 \times 10^{-7}$ & $1.9 \times 10^{-6}$ & $1.8 \times 10^{-6}$ \\
\hline 14 & SCL & $1.70 \times 10^{-6}$ & $1.5 \times 10^{-6}$ & $1.4 \times 10^{-6}$ & $7.1 \times 10^{-7}$ & $3.2 \times 10^{-6}$ & $3.0 \times 10^{-6}$ \\
\hline 15 & SCL & $1.30 \times 10^{-6}$ & $1.5 \times 10^{-6}$ & $1.1 \times 10^{-6}$ & $1.8 \times 10^{-6}$ & $2.5 \times 10^{-6}$ & $2.4 \times 10^{-6}$ \\
\hline 16 & $\mathrm{SCL}$ & $2.30 \times 10^{-7}$ & $1.5 \times 10^{-6}$ & $1.0 \times 10^{-6}$ & $4.9 \times 10^{-7}$ & $5.2 \times 10^{-7}$ & $5.9 \times 10^{-7}$ \\
\hline 17 & $\mathrm{SCL}$ & $1.04 \times 10^{-6}$ & $1.5 \times 10^{-6}$ & $1.1 \times 10^{-6}$ & $8.3 \times 10^{-7}$ & $1.6 \times 10^{-6}$ & $1.6 \times 10^{-6}$ \\
\hline 18 & SCL & $1.30 \times 10^{-6}$ & $1.5 \times 10^{-6}$ & $7.6 \times 10^{-7}$ & $7.4 \times 10^{-7}$ & $1.7 \times 10^{-6}$ & $1.6 \times 10^{-6}$ \\
\hline
\end{tabular}




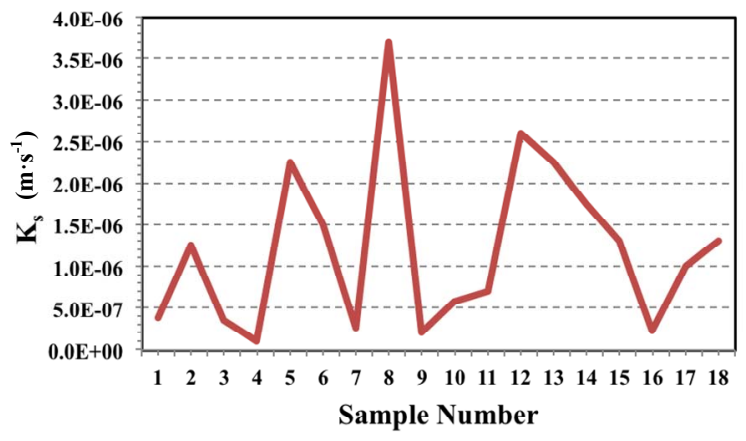

Figure 4. Measured values of saturated hydraulic conductivity $\left(K_{s}, \mathrm{~m} \cdot \mathrm{s}^{-1}\right)$ for the 18 soil samples of the field in Lamesa, Texas.

from a low of $3.5 \times 10^{-8} \mathrm{~m} \cdot \mathrm{s}^{-1}$ at location 4 , a sandy clay loam texture, to a high of $3.7 \times 10^{-6} \mathrm{~m} \cdot \mathrm{s}^{-1}$ at location 8 , a sandy clay texture. Soil sample number 8 corresponds to

(a) Textural Class $=\mathrm{Hl}$

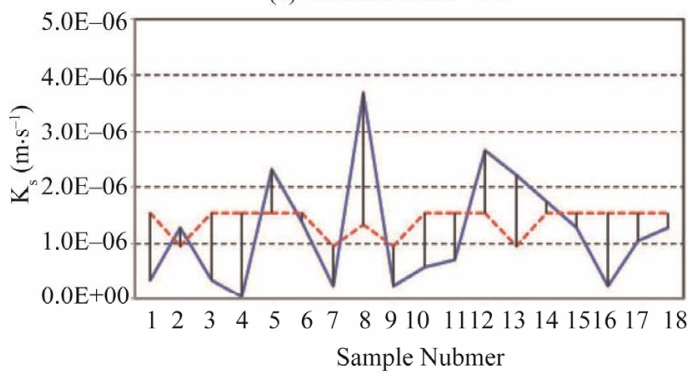

(c) $\mathrm{H} 2+$ Soil Bulk Density $=\mathrm{H} 3$

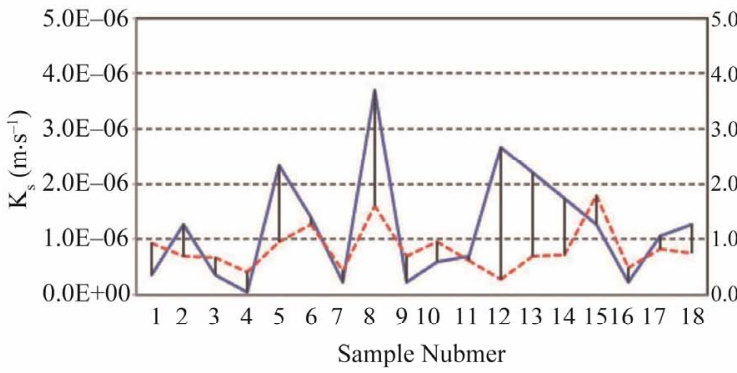

a sandy clay; whereas, samples 2, 7, 9 and 13 are a clay loam. The rest of the soil samples $(1,3,4,5,6,10,11,12$, 14, 15, 16, 17 and 18) were sandy clay loam. From Figure 4 , it is clear that the sandy clay sample 8 has the higher $K_{s}$; whereas, the clay loam (samples $2,7,9,13$ ) is as random as the sandy clay loam. The average $K_{\mathrm{s}}$ was $1.20 \times 10^{-6} \mathrm{~m} \cdot \mathrm{s}^{-1}$ with a standard deviation of $9.95 \times 10^{-7}$ $\mathrm{m} \cdot \mathrm{s}^{-1}$. The high variation could be the result that these soil samples were from a plowed layer and invariably some compression occurred during sampling confirming that $K_{s}$ is problematic to measure due to its associated variability and uncertainty [21].

\subsection{Rosetta Simulations}

Results from comparing measured values of $K_{s}$ with those obtained with the five levels of Rosetta are given in Table 4 and plotted in Figure 5. As previously, des-

(b) $\mathrm{H} 1+($ Sand, Silt, and Clay $)=\mathrm{H} 2$

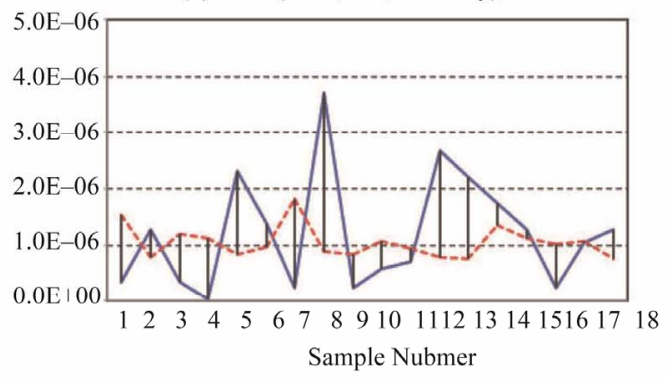

(d) $\mathrm{H} 3+$ Soil Water Content at $-33 \mathrm{kPa}=\mathrm{H} 4$

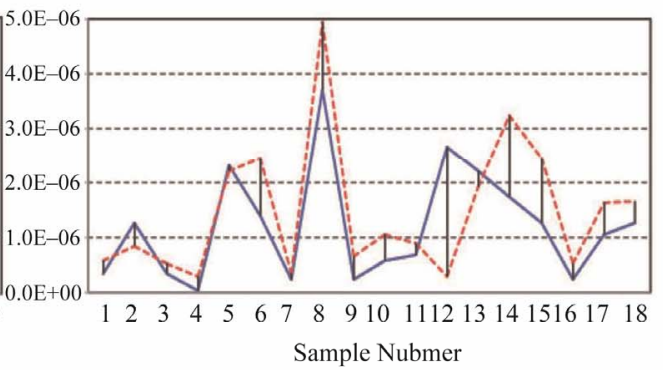

(e) $\mathrm{H} 4+$ Soil Water Content at $-1500 \mathrm{kPa}=\mathrm{H} 5$

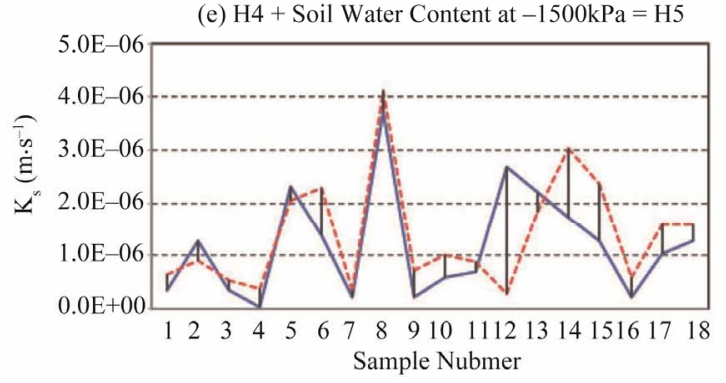

Figure 5. Comparison of measured and calculated values of saturated hydraulic conductivity $\left(K_{s}, \mathrm{~m} \cdot \mathrm{s}^{-1}\right)$ for 18 locations of a field in Lamesa, Texas. Calculated values of $K_{s}$ were obtained with the Rosetta PTF [14]. (a) Textural class, level H1; (b) H1 plus sand, silt and clay, level $\mathrm{H} 2$; (c) $\mathrm{H} 2$ plus soil dry-bulk density, level $\mathrm{H3}$; (d) $\mathrm{H3}$ plus soil water content at $-33 \mathrm{kPa}$, level $\mathrm{H4}$; and (e) $\mathrm{H} 4$ plus soil water content at $-1500 \mathrm{kPa}$, level $\mathrm{H5}$. 
cribed, Rosetta uses a hierarchical approach and each level $\mathrm{H}$ is based on the previous one plus an additional surrogate measurement. Five simulations were run with Rosetta and the results for each level of $\mathrm{H}$ are plotted in Figures 5(a)-(e).

The input data used in all Rosetta simulations is given in Table 5. These results show that level H1 Rosetta, which calculates $K_{s}$ using USDA textural class input does not follow the pattern of the measured values (Figure 5(a)). The RMSD between measured and calculated values of $K_{s}$ obtained in this case was $1.03 \times 10^{-6} \mathrm{~m} \cdot \mathrm{s}^{-1}$ and the NSE was -0.10 . Both statistical parameters suggest that the values of $K_{s}$ obtained with level H1 of Rosetta were wrong for this particular field and this result was confirmed with the low value of $\mathrm{R}^{2}$ (Figure 6(a)). When the percentage of sand, silt and clay is used, i.e. level $\mathrm{H} 2$ of Rosetta, the RMSD between measured and calculated values of $K_{s}$ was $1.15 \times 10^{-6}$, NSE was -0.3 and $\mathrm{R}^{2}$ was 0.22 (Figure 6(b)), slightly better than values obtained with level H1, but also incorrect. Adding the soil drybulk density, $\rho_{\mathrm{b}}$, to the Rosetta input, i.e. level $\mathrm{H} 3$, shows some improvement with an RMSD of $9.8 \times 10^{-7} \mathrm{~m} \cdot \mathrm{s}^{-1}$ and NSE is 0 with an $\mathrm{R}^{2}=0.15$ (Figure 6(c)). For the next level of Rosetta, H4 that uses textural infor- mation, $\rho_{\mathrm{b}}$ and soil volumetric water content, $\theta$, at $h=$ $-33 \mathrm{kPa}$ as input, the RMSD was $8.63 \times 10^{-7} \mathrm{~m} \cdot \mathrm{s}^{-1}$, the $\mathrm{NSE}$ is 0.22 and $\mathrm{R}^{2}=0.55$ (Figure $6(\mathbf{d})$ ). In $\mathrm{H} 4$, the variability of the measured values of $K_{s}$ (from $2.3 \times 10^{-7}$ to $2.7 \times 10^{-6} \mathrm{~m} \cdot \mathrm{s}^{-1}$ for sandy clay loam) is larger than the RMSD. Finally, using level H5 of Rosetta, which requires input values of sand, silt and clay, $\rho_{\mathrm{b}}$, and $\theta$ at $\mathrm{h}=$ -33 and $-1500 \mathrm{kPa}$, yields an RMSD of $7.81 \times 10^{-7}$ $\mathrm{m} \cdot \mathrm{s}^{-1}$, NSE of 0.36 , and $\mathrm{R}^{2}=0.51$ (Figure 6(e)). This level of Rosetta calculated values of $K_{s}$ with the smallest RMSD and largest NSE.

\section{Summary and Conclusions}

All water flow and solute transport modeling in soils need as crucial input the $K_{s}$ [3]. Also $K_{s}$ is a sensitive parameter in hydrological models and one of the most problematic measurements at field-scale in regard to variability and uncertainty [21]. This study tested the application of the pedotransfer function Rosetta to identify the level of input needed in order to use Rosetta as a tool to calculate the $K_{s}$ for a 64 ha field in the Southern High Plains of Texas.

Rosetta calculations of $K_{s}$ improved with a RMSD of

Table 5. Measured values of sand, silt, clay, dry-bulk density $\left(\rho_{\mathrm{d}}, \mathrm{kg} \cdot \mathrm{m}^{-3}\right)$, and soil volumetric water content $(\theta)$ at a suction of $-33 \mathrm{kPa}$ and $-1500 \mathrm{kPa}$ for the 18 locations shown in Figure 2.

\begin{tabular}{|c|c|c|c|c|c|c|}
\hline Location & Sand $\%$ & Silt \% & Clay \% & $\rho_{\mathrm{b}}\left(\mathrm{kg} \cdot \mathrm{m}^{-3}\right)$ & $\theta-33 \mathrm{kPa}$ & $\theta-1500 \mathrm{kPa}$ \\
\hline 1 & 59.2 & 15.2 & 25.6 & 1680 & 0.29 & 0.06 \\
\hline 2 & 44.9 & 24.6 & 30.5 & 1580 & 0.30 & 0.05 \\
\hline 3 & 51.1 & 22.9 & 26.0 & 1670 & 0.29 & 0.13 \\
\hline 4 & 53.1 & 17.5 & 29.4 & 1780 & 0.29 & 0.06 \\
\hline 5 & 46.5 & 19.8 & 33.7 & 1540 & 0.28 & 0.14 \\
\hline 6 & 49.0 & 17.5 & 33.6 & 1510 & 0.29 & 0.14 \\
\hline 7 & 32.0 & 47.8 & 20.2 & 1710 & 0.30 & 0.17 \\
\hline 8 & 46.9 & 18.4 & 34.7 & 1440 & 0.27 & 0.14 \\
\hline 9 & 46.5 & 19.8 & 33.7 & 1600 & 0.32 & 0.16 \\
\hline 10 & 52.0 & 16.4 & 31.6 & 1600 & 0.30 & 0.23 \\
\hline 11 & 49.4 & 20.1 & 30.5 & 1660 & 0.28 & 0.15 \\
\hline 12 & 45.5 & 21.5 & 32.9 & 1790 & 0.29 & 0.17 \\
\hline 13 & 44.9 & 21.7 & 33.4 & 1580 & 0.27 & 0.18 \\
\hline 14 & 54.3 & 20.2 & 25.4 & 1690 & 0.20 & 0.13 \\
\hline 15 & 53.1 & 17.5 & 29.4 & 1480 & 0.29 & 0.15 \\
\hline 16 & 50.7 & 17.5 & 31.8 & 1720 & 0.29 & 0.11 \\
\hline 17 & 52.1 & 16.4 & 31.5 & 1630 & 0.27 & 0.15 \\
\hline 18 & 59.2 & 15.2 & 25.6 & 1680 & 0.29 & 0.06 \\
\hline
\end{tabular}


(a) Textural Class $=\mathrm{H} 1$

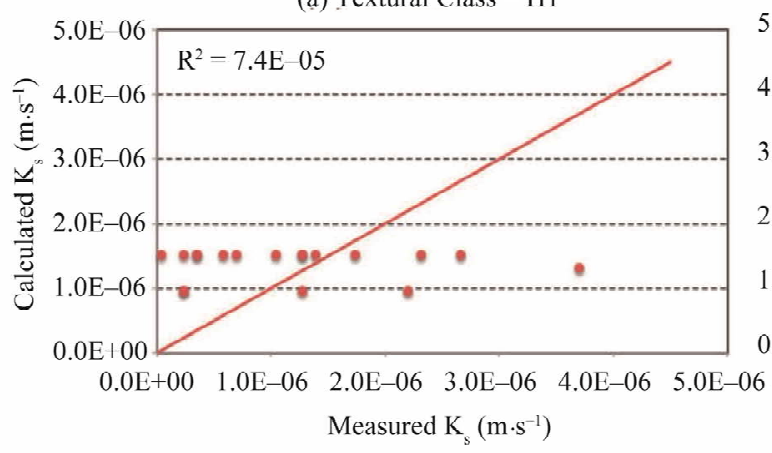

(c) $\mathrm{H} 2+$ Soil Bulk Density $=\mathrm{H} 3$

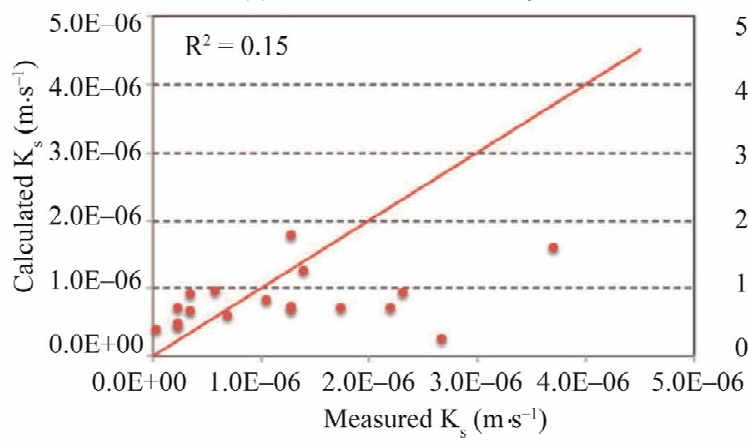

(b) $\mathrm{H} 1+($ Sand, Silt, and Clay) $=\mathrm{H} 2$

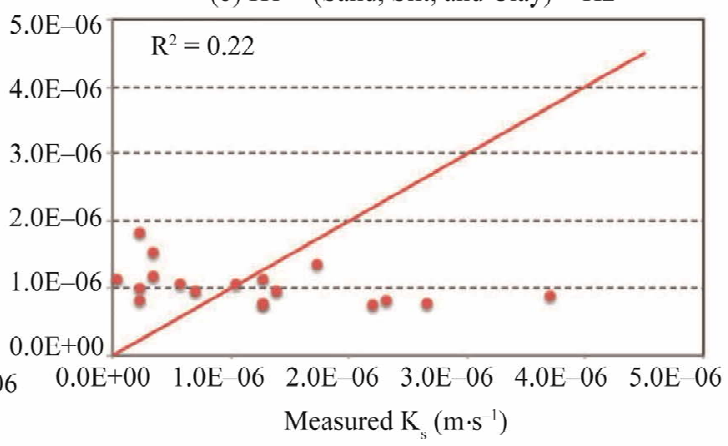

(d) $\mathrm{H} 3+$ Soil Water Content at $-33 \mathrm{kPa}=\mathrm{H} 4$

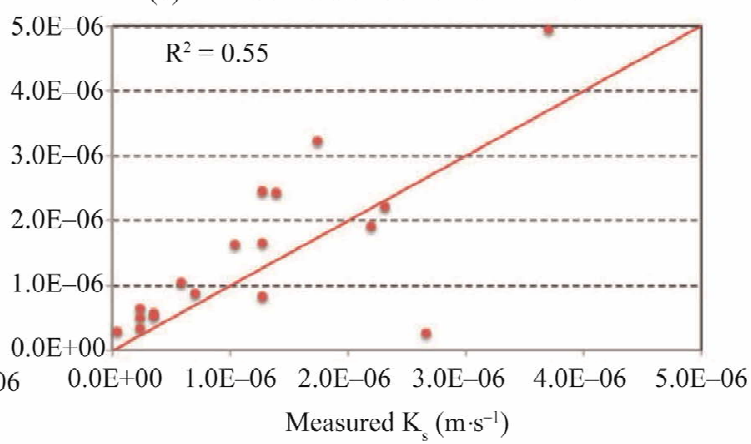

(c) $\mathrm{H} 4+$ Soil Water Content at $-1500 \mathrm{kPa}-\mathrm{H} 5$

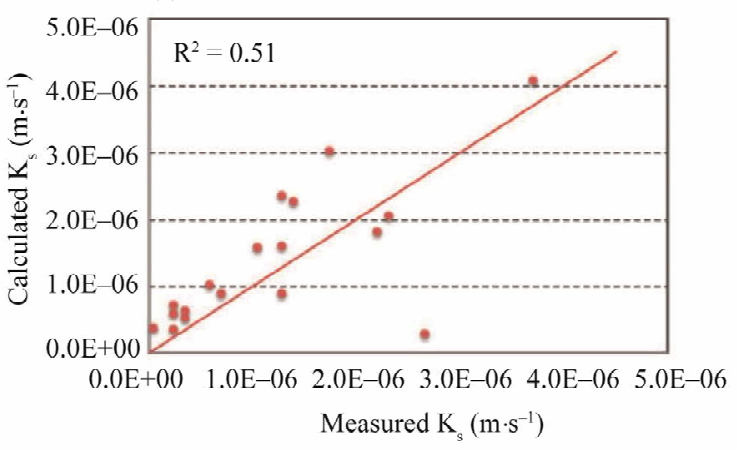

Figure 6. Linear regression between calculated and measured values of saturated hydraulic conductivity $\left(K_{s}, \mathbf{m} \cdot \mathrm{s}^{-1}\right)$. Calculated values of $K_{s}$ were obtained with five hierarchical levels of the Rosetta PTF. (a) Textural class, level H1; (b) H1 plus sand, silt and clay, level $\mathrm{H2}$; (c) $\mathrm{H} 2$ plus soil dry-bulk density, level $\mathrm{H3}$; (d) H3 plus soil water content at $\mathbf{- 3 3} \mathrm{kPa}$, level $\mathrm{H4}$; and (e) $\mathrm{H4}$ plus soil water content at $-1500 \mathrm{kPa}$, level $\mathrm{H5}$. The line plotted is the $1: 1$ and the linear regression coefficient $\left(\mathrm{R}^{2}\right)$ for each level of $H$ is shown in the upper left hand corner.

$1.03 \times 10^{-6} \mathrm{~m} \cdot \mathrm{s}^{-1}$ and NSE -0.1 when only using the USDA textural class as input to a RMSD of $9.8 \times 10^{-7}$ $\mathrm{m} \cdot \mathrm{s}^{-1}$ and NSE of 0 , when the $\rho_{\mathrm{b}}$ was added. The NSE indicates that with the textural information only, the measured mean value of $K_{s}$ is a better predictor than the model. However, when the $\rho_{\mathrm{b}}$ was added Rosetta calculations were as accurate as the mean of the measured values. These values were further improved when $\theta$ at $h$ $=-33 \mathrm{kPa}$ was added as input; the RMSD was reduced to $8.63 \times 10^{-7} \mathrm{~m} \cdot \mathrm{s}^{-1}$ and the NSE increased to 0.2 . Furthermore, with the addition of the soil volumetric water content, $\theta$, at $h=-1500 \mathrm{kPa}$, the RMSD decreased to $7.81 \times$
$10^{-7} \mathrm{~m} \cdot \mathrm{s}^{-1}$ and the NSE increased to 0.36 . Once $\theta$ information is introduced the NSE is positive, which means that Rosetta does better predictions that the mean of the measured values. Based on these results we conclude that Rosetta PTF is a useful tool that can be used to calculate $K_{s}$ in the absence of measured values and that for this particular soil, the hierarchical level 5 of Rosetta yielded the best results with the measured input data. The better prediction of $K_{s}$ by using the hierarchical level 5 of the PTF Rosetta confirms then findings of Gülser et al. [20] who used the same input parameters to calculate saturated hydraulic conductivity, $K_{s}$. 


\section{Acknowledgements}

The authors would like to thank Jill and J. D. Booker aswell as John Randall Nelson and Vinicius Bufon from the USDA-ARS Cropping Systems Research Laboratory, Lubbock, Texas, for their assistance in the field and laboratory work.

\section{REFERENCES}

[1] C. M. Rubio, P. Llorens and F. Gallart, "Uncertainty and Efficiency of Pedotransfer Functions for Estimating Water Retention Characteristics of Soils," European Journal of Soil Science, Vol. 59, No. 2, 2008, pp. 339-347. doi:10.1111/j.1365-2389.2007.01002.x

[2] O. Vigiak, S. J. E. van Dijck, E. E. van Loon and L. Stroosnijder, "Matching Hydrologic Response to Measured Effective Hydraulic Conductivity," Hydrological Processes, Vol. 20, No. 3, 2006, pp. 487-504. doi:10.1002/hyp.5916

[3] J. H. M. Wösten, Y. A. Pachepsky and W. J. Rawles, "Pedotransfer Functions: Bridging the Gap between Available Basic Soil Data and Missing Soil Hydraulic Characteristics," Journal of Hydrology, Vol. 251, No. 3-4, 2001, pp. 123-150. doi:10.1016/S0022-1694(01)00464-4

[4] S. R. Evett and R. J. Lascano, "ENWATBAL.BAS: A Mechanistic Evapotranspiration Model Written in Compiled Basic," Agronomy Journal, Vol. 85, No. 3, 1993, pp. 763-772.

doi:10.2134/agronj1993.00021962008500030044x

[5] R. J. Lascano, "A General System to Measure and Calculate Daily Crop Water Use," Agronomy Journal, Vol. 92, No. 5, 2000, pp. 821-832. doi:10.2134/agronj2000.925821x

[6] J. Šimünek, M. Šejna and M. T. van Genuchten, "The Hydrus-2D Software Package for Simulating the TwoDimensional Movement of Water, Heat, and Multiple Solutes in Variably-Saturated Media. IGWMC-TPS 53251 v. 2.0," Colorado School of Mines International, Ground Water Modeling Center Golden, Colorado, 1999.

[7] D. E. Radcliffe and J. Šimünek, "Soil Physics with HYDRUS Modeling and Applications," CRC Press, Boca Raton, 2010.

[8] C. C. Molling, "Precision Agricultural-Landscape Modeling System. Version 5. Combined User's and Developer's Manual," University of Wisconsin Board of Regents, Wisconsin, 2008.

[9] C. C. Molling, J. C. Strikwerda, J. N. Norman, C. A. Rodgers, R. Wayne, C. L. S. Morgan, G. R. Diak and J. R. Mecikalski, "Distributed Runoff Formulation Designed for a Precision Agricultural Landscape Modeling System," Journal of the American Water Resources Association, Vol. 41, No. 6, 2005, pp. 1289-1313. doi:10.1111/j.1752-1688.2005.tb03801.x

[10] C. L. S. Morgan, "Quantifying Soil Morphological Properties for Landscape Management Applications," Ph.D. Dissertation, University of Wisconsin-Madison, Wisconsin, 2003.

[11] H. Aksoy and M. L. Kavvas, "A Review of Hillslope and
Watershed Scale Erosion and Sediment Transport Models," Catena, Vol. 64, No. 2-3, 2005, pp. 247-271. doi:10.1016/j.catena.2005.08.008

[12] M. G. Schaap and F. J. Leij, "Using Neural Networks to Predict Soil Water Retention and Soil Hydraulic Conductivity," Soil and Tillage Research, Vol. 47, No. 1-2, 1998, pp. 37-42. doi:10.1016/S0167-1987(98)00070-1

[13] W. Aimrun and M. S. M. Amin, "Pedo-Transfer Function for Saturated Hydraulic Conductivity of Lowland Paddy Soils," Paddy Water Environment, Vol. 7, No. 3, 2009, pp. 217-225. doi:10.1007/s10333-009-0165-y

[14] M. G. Schaap, F. J. Leij and M. T. van Genuchten, "Rosetta: A Computer Program for Estimating Soil Hydraulic Parameters with Hierarchical Pedotransfer Functions," Journal of Hydrology, Vol. 251, No. 3-4, 2001, pp. 163-176. doi:10.1016/S0022-1694(01)00466-8

[15] L. Stroosnijder, "Measurement of Erosion: Is It Possible?" Catena, Vol. 64, No. 2-3, 2005, pp. 162-173. doi:10.1016/j.catena.2005.08.004

[16] W. J. Rawles and D. L. Brakensiek, "Estimating SoilWater Retention from Soil Properties," Journal of the Irrigation and Drainage Division, Vol. 108, No. 2, 1982, pp. 166-171.

[17] A. B. McBratney, B. Minasny, S. R. Cattle and R. W. Vervoort, "From Pedotransfer Functions to Soil Inference Systems," Geoderma, Vol. 109, No. 1-2, 2002, pp. 41-73. doi:10.1016/S0016-7061(02)00139-8

[18] Y. Pachepsky, D. E. Radcliffe and H. M. Selim, "Scaling Methods in Soil Physics," CRC Press, New York, 2003.

[19] K. Parasuraman, A. Elshorbagy and B. C. Si, "Estimating Saturated Hydraulic Conductivity in Spatially Variable Fields Using Neural Network Ensembles," Soil Science Society of America Journal, Vol. 70, No. 6, 2006, pp. 1851-1859. doi:10.2136/sssaj2006.0045

[20] C. Gülser and F. Candemir, "Prediction of Saturated Hydraulic Conductivity Using Some Moisture Constants and Soil Physical Properties," Proceeding Balwois, Ohrid, 31 May 2008.

[21] R. Muñoz-Carpena, C. M. Regalado, J. Alvarez-Benedi and F. Bartoli, "Field Evaluation of the New PhilipDunne Permeameter for Measuring Saturated Hydraulic Conductivity," Soil Science, Vol. 167, No. 1, 2002, pp. 924. doi:10.1097/00010694-200201000-00002

[22] M. Mbonimpa, M. Aubertin, R. P. Chapuis and B. Bussière, "Practical Pedotransfer Functions for Estimating the Saturated Hydraulic Conductivity," Geotechnical and Geological Engineering, Vol. 20, 2002, pp. 235-259. doi:10.1023/A:1016046214724

[23] K. Kobayashi and M. U. Salam, "Comparing Simulated and Measured Values Using Mean Squared Deviation and Its Components," Agronomy Journal, Vol. 92, No. 2, 2000, pp. 345-352. doi:10.2134/agronj2000.922345x

[24] D. N. Moriasi, J. G. Arnold, M. W. Van Liew, R. L. Bingner, R. D. Harmel and T. L. Veith, "Model Evaluation Guidelines for Systematic Quantification of Accuracy in Watershed Simulations," Transactions of the ASABE, Vol. 50, No. 3, 2007, pp. 885-900.

[25] P. D. Colaizzi, P. H. Gowda, T. H. Marek and D. O. Por- 
ter, "Irrigation in the Texas High Plains: A Brief History and Potential Reductions in Demand," Irrigation and Drainage, Vol. 58, No. 3, 2009, pp. 257-274. doi:10.1002/ird.418

[26] NRCS, “Official Series Description," 2008. http://www2.ftw.nrcs.usda.gov/osd/dat/A/ACUFF.html

[27] C. Stumpp, S. Engelhardt, M. Hofmann and B. Huwe, "Evaluation of Pedotransfer Functions for Estimating Soil Hydraulic Properties of Prevalent Soils in a Catchment of the Bavarian Alps," European Journal of Forest Research, Vol. 128, No. 6, 2009, pp. 609-620. doi:10.1007/s10342-008-0241-7

[28] Y. Mualem, "New Model Evaluation Guidelines for Systematic Quantification of Accuracy in Watershed Simulations," Water Resources Research, Vol. 12, No. 3, 1976, pp. 513-522. doi:10.1029/WR012i003p00513

[29] M. T. van Genuchten, "A Closed-Form Equation for Predicting the Hydraulic Conductivity of Unsaturated Soils," Soil Science Society American Journal, Vol. 44, No. 5, 1980, pp. 892-898. doi:10.2136/sssaj $1980.03615995004400050002 x$

[30] G. J. Bouyoucos, "Hydrometer Method Improved for Making Particle Size Analyses of Soils," Agronomy Journal, Vol. 54, No. 5, 1962, pp. 464-465. doi:10.2134/agronj1962.00021962005400050028x

[31] A. Klute, R. C. Dinauer, A. L. Page, R. H. Miller and D. R. Keeney, "Methods of Soil Analysis. Part 1. Physical and Mineralogical Methods," Soil Science Society of America, Madison, 1986.

[32] Eijkelkamp, "Laboratory Permeameter. Operating Instructions," 2008

http://www.eijkelkamp.com/Portals/2/Eijkelkamp/Files/ Manals/M10902e\%20Laboratory\%20permeameters.pdf

[33] Eijkelkamp, "Sand/Kaolin Box," 2005. http://www.eijkelkamp.com/Portals/2/Eijkelkamp/Files/ Manuals/M10802e\%20Sand\%20kaolin\%20box.pdf

[34] Eijkelkamp, "Pressure Membrane Apparatus," 2005. http://www.eijkelkamp.com/Portals/2/Eijkelkamp/Files/ Manuals/M10803e\%20Pressure\%20membrane.pdf 